Portfolio: Where Geography and Photography Meet", it contains 84 plates in both color and black and white.

This monograph joins a relatively small group of publications that successfully capture the sense of history and place of a metropolitan region in a manner accessible to a general audience while providing sufficient detail to satisfy the needs of most academic readers. While it is customary for reviewers to point out limitations and weaknesses as well as strengths; here it is the strengths that are much more evident. It might have been helpful for ease of comparison, however, had more of the statistical maps been drawn on the same base map and had those maps displaying data measured across other spatial units also been at the same scale. Insets might also have been included for maps displaying patterns both within the city of Chicago and its metropolitan region, to better show detail in more densely populated areas. While the text references many important historical and contemporary resources and studies, the list of references and selected readings is just that; a list, requiring real effort on the part of the truly engaged reader wishing to delve more deeply into the historical and contemporary geography of this great city. These are, nonetheless, but passing concerns regarding what is otherwise an outstanding work of scholarship and literature. In Chicago: A Geography of the City and Its Region, John C. Hudson has set an example to which we all might aspire; integrating visual images, maps, history, physical, social and economic geography into a tapestry that at once helps the reader understand where things are, where they may be going, and where they have been.

\section{Permissions, A Survival Guide: Blunt Talk about Art} as Intellectual Property

By Susan Bielstein

Chicago: The University of Chicago Press, 2006.

177 pp., black and white illustrations, $\$ 30.00$ (US).

Hardcover, ISBN 0-226-04637-0

Reviewed by Mary L. Johnson

Technical Writer

Remington \& Vernick Engineers

Haddonfield, New Jersery

www.rve.com

Susan M. Bielstein is Executive Editor for Art, Architecture, Classical Studies, and Film at the University of Chicago Press. She is also a trustee of the Graham Foundation for Advanced Studies in the Fine Arts. Even without an awareness of these impressive credentials, the reader has the sense from the outset that the author has a thorough and "inside" understanding of the subject she is presenting.
Permissions deals largely with "art books;" the sort of book with lavish illustrations and scholarly subject matter that could be used as reference or proudly displayed on one's coffee table. The illustrations in these volumes, which often consist of reproduced artwork, photographs of artwork, or photographs in general, are becoming increasingly difficult to obtain for commercial use. The fees associated with licenses, usage and reproduction are simply too costly for publications that may have limited interest and print runs.

As the author herself states, this book is not intended as a complete explanation of copyright law. The main focus of the book is to define what a copyright is, and how the existence or non-existence of a copyright can influence your use of an image or photograph. There are guidelines presented for determining whether or not a work is copyrighted, what constitutes "fair use" of an image, and how to acquire an image in publishable or otherwise usable format suited to a particular project.

Although the examples provided in Permissions are related to the publication of art books, they can also be applied to the use of copyrighted images in any type of publication. Copyright law is important to cartographers as well, since maps are highly sought after for inclusion in a wide variety of visual media.

Copyright laws vary from country to country, so it is important to understand the origin of an image being considered for publication. In the United States, the following key points roughly define existing copyright laws:

- Anything created since 1978 is currently protected under copyright law.

- Unpublished artwork created before 1978 is protected under copyright law for the life of the artist plus an additional seventy years.

- Unpublished artwork created by an artist who died before 1932 entered the public domain no later than 2002 , and is therefore usable without permission.

- Anything published before 1923 is considered in the public domain and therefore usable without permission.

- Many works published between 1923 and the present are still protected by copyright law.

This sounds relatively straightforward, but there are a number of interesting twists and turns that make judging the need for permission to use an image in the first place, and ultimately acquiring that permission, very complicated. For example, does a photograph of an existing artwork that is already in the public domain constitute a separate work of art in itself? If so, would that photograph be subject to copyright protection even if the artwork it represented was not?

If a photograph is taken of a three-dimensional work, such as a sculpture or statue, it often involves 
creative lighting and the careful consideration of which angle would be best for photographic effect. A photograph made in this manner is considered an interpretative image and is therefore subject to copyright protection, even if the subject of the photograph is already in the public domain. However, if a photograph is made of a two-dimensional work, such as a painting or map, and was simply made to document the existence of an artwork in the public domain, it is considered a slavish copy and is not subject to copyright protection.

What about photographs taken of people, or with people appearing in them even if the people themselves are not the subject? It is understood that permission to publish a photograph of a person is generally not necessary if the person in the photograph is not recognizable to others. This might include people well in the distance, or camouflaged somehow by light or shadow. If a person in the photograph is recognizable to others, then permission from that person would be required before the image could be printed.

There are additional issues concerning where and how a photograph of a person or event was taken. Does it center around a public place or public gathering? Or does it represent uninvited intrusion and documentation of a private location or event? These issues often come into play when celebrities are photographed. A celebrity is considered fair game for photographers in public, but not in private surroundings. After all, a celebrity is a celebrity in the first place by virtue of capitalizing on his or her own public appeal. Part of being a celebrity is accepting, or perhaps even inviting, a certain amount of publicity. However, a photographer crosses the line when photographing a celebrity in private surroundings or during a private event without obtaining permission to do so. Even the biggest celebrity is entitled to some amount of privacy.

Another issue involves unsolicited photographs that will ultimately interfere with or lessen the value of previously solicited photographs. For example, when celebrities have babies, the rights to publish the first photographs of the babies are often highly coveted and exorbitantly expensive, but the publisher hopes to recoup these costs many times over once the photographs are published. Therefore, if another photographer manages to take an unsolicited photograph of the baby and has it published prior to the solicited work, it can damage the commercial value of the solicited work. What may initially seem like quite a coup for the unsolicited photographer will most likely result in a lawsuit and punitive damages once the deed has been made public.

When photographing a private individual, even in a public setting, permission must be gained if the person is recognizable in the photograph, since non-celebrities do not capitalize on their public appeal and do not necessarily want to see their images splashed all over the printed or visual media. When a photographer is requesting permission to use a photograph of a private individual, it should be expressly stated that complete rights to the image are being solicited. Any compensation being offered to the subject in return for those rights should be clearly spelled out in the permission paperwork.

"Fair use" is a concept related to copyright law, but is not a law itself. Fair use involves using someone else's copyrighted work for a particular purpose, while recognizing that the work's original ownership remains unchanged. There are several important factors that define fair use:

- The purpose and character of the intended use should not transform the original work.

- If the nature of the original copyrighted work is factual, the facts themselves are not subject to copyright protection, but the way the facts are presented in the original work are subject to copyright protection.

- Only a small percentage of the original copyrighted work can be used or quoted in relation to the original copyrighted work as a whole.

- The new work incorporating fair use cannot infringe upon the potential market value of the original copyrighted work, nor can it otherwise compete with the original work.

For educational purposes, it is considered acceptable to use a slide or digital file of a copyrighted work as a teaching resource, for research purposes, or within a thesis. However, you cannot subsequently publish these new works without permission. It is also considered acceptable to get an idea from a copyrighted work and then incorporate the idea itself into a new work, but it is not acceptable to simply copy an existing work in another medium.

Style is another commodity that cannot be copyrighted. Looking at maps, for example, it would be acceptable to produce an entirely new map in the overall style of another without infringing on the original's copyright.

If the intended use of an original does not fall under the concept of fair use, it will be necessary to gain permission before the original can be incorporated into a new work. When requesting permission to use any image, it is important to explain exactly how the work will be used, including who will publish it, what type of media it will be in, where it will appear in a book (inside or on the cover), whether the image will be reproduced in color or black and white, and how many copies are expected to be printed. It may also be necessary to describe any caption or associated text that will be devoted to the image.

It may take some research to determine exactly 
what individual, group or organization holds the rights to a particular work. In addition to the artist or artist's estate, there are image warehouses, museums, libraries and artists rights organizations. Permissions provides contact information for image banks, search engines and artists' representatives that may help in this quest. Potential publishers will generally require that appropriate rights be obtained before a book is published. The author is generally responsible for the costs and documentation involved.

Acceptable formats for images destined for publication are transparency/slide, high resolution digital files, or photographic prints. Transparencies are preferred, since they are the closest to the original work. Suppliers of transparencies will generally license their use for a limited period, rather than selling them outright, so it is important to establish an acceptable timeframe and/or gain an extension so that the work will be available throughout the publication process. A good transparency includes a color bar to help printers reproduce the image as faithfully to the original as possible.

When submitting digital images for publication, it is important to use the format and resolution guidelines outlined by a potential publisher. Images should be submitted on CD or DVD rather than attached to an e-mail. The current industry standard for digital image resolution is 300 pixels per inch (ppi). Permissions offers examples of illustrations that were reproduced at the appropriate resolution, at a lesser resolution, and even at a lesser resolution that was enhanced with image software. The comparisons demonstrate the importance of meeting the 300 ppi standard.

Many works in the public domain can be downloaded directly from the United States Library of Congress. Other works are available only for research or educational use. Always check the fine print for any usage restrictions.

Permissions provides the source of each illustration within its covers, as well as a complete account of copyright fees and related use fees. The total fee required to obtain and use the black and white illustrations included in the book was $\$ 1,511.18$. Additional examples are provided from other authors that involve even greater costs. No wonder Bielstein expresses her concern about the future of art books.

Bielstein offers some creative suggestions for negotiating better usage rates, including the substitution of a percentage of the author's royalty fees for an actual licensing or reprographic fee. The percentage paid would be based on what percentage of the overall book will be taken up by the image involved. For example, a full-page image in a 200-page book would involve $1 / 200$ of the author's royalty.

Sample form letters for obtaining copyright or use permissions are included in the back of the book.
These provide important insight and guidance for those wishing to publish copyrighted artwork. Bielstein also recommends that copyrighted artwork only be used when absolutely necessary in order to conserve costs and avoid lengthy negotiations. There may be equally usable works in the public domain, or a particular image may not complement the text enough to make the extra costs and wrangling worthwhile.

Since copyright law has long been associated with books and illustrations available in traditional "hardcopy" formats, the easy accessibility and sheer volume of data increasingly available online must be testing the concept of "fair use" in ways that could never have been foreseen when copyright law was last revised in 1978. I had hoped that Bielstein's book would explore this timely subject in greater detail, and that at least one chapter might be devoted to the obvious issues involved when publishing or using material online. However, Bielstein provides limited guidance on electronic media, and instead refers readers to other authors and books that might offer a more thorough understanding of this topic.

In spite of this one drawback, I found Permissions to be a very comprehensive book that is entirely true to its stated purpose. I would highly recommend it to anyone considering compiling and publishing a book or article that will rely heavily on artwork, images or even maps created by others. Permissions provides important insight into the forms, contacts and fees associated with finding and using copyrighted illustrations. The book is informative without being boring, and the complicated subject matter is presented in a light and understandable fashion. Permissions is aimed at the layperson and not at the legal profession.

For readers who are not compiling a heavily illustrated art publication, this book is useful from a different perspective. Many people, particularly in the academic world, will ultimately want to publish articles, papers or similar works of their own creation, with or without incorporating the illustrations of others. Cartographers may be asked to provide maps for publication in books, periodicals or atlases being compiled by other sources. Permissions provides a valuable source of reference for the author, artist or cartographer wondering about the intricate elements of copyright protection as applied to his or her own creative work. It is important for anyone involved in the arts, whether literary or cartographic, to understand the level of control that can or cannot be exerted once a work has been published or otherwise publicly displayed. The concept of "fair use," although not open-ended, is one that must continue to work both ways in order to survive and prosper. 